\title{
Loose anagen syndrome
}

INSERM

\section{Source}

INSERM. (1999). Orphanet: an online rare disease and orphan drug data base. Loose anagen syndrome. ORPHA:168

Loose anagen syndrome is a rare benign hair disorder affecting predominantly blond females in childhood and characterized by the presence of hair that can be easily and painlessly pulled out. Most of the hair is in the anagen phase and lacks an external epithelial sheath. Hair grows back quickly and the condition improves spontaneously with aging. Loose anagen hair can be associated with other anomalies, such as coloboma. 